\title{
Cryo-EM of small proteins using designed assemblies as modular scaffolds
}

\author{
Todd O. Yeates ${ }^{a}$, Yuxi, Liu ${ }^{b}$, Duc Huynh ${ }^{c}$ and Matthew Agdanowskid \\ aUCLA Department of Chemistry and Biochemistry, Los Angeles, CA 90095, USA \\ yeates@mbi.ucla.edu \\ blbid., yuxiliu@chem.ucla.edu \\ 'Ibid., ductanhuynh13@ucla.edu \\ d Ibid., magdanowski@gmail.com
}

Current advanced in cryo-electron microscopy have enabled the atomic level structure determination of extraordinary structures from viruses to large protein and nucleic acid complexes. However, signal-to-noise limitations make it extremely difficult to apply cryo-EM techniques to macromolecules smaller than about $50 \mathrm{kDa}$ [1]. Breaking through this lower size limit is a key goal for the field, given that the average size for cellular proteins is in the 20 to 30 $\mathrm{kDa}$ range.

Recent developments in protein design have made it possible to create highly geometric protein assemblies, like cubic cages or clusters, with atomic level accuracy $[2,3]$. In new work we have used designed assemblies as scaffolds to which other small 'cargo' proteins can be attached for imaging by cryo-EM $[4,5]$. Two key challenges have been addressed in our scaffold designs. First, semi-rigid display of a cargo protein has been demonstrated using continuous alpha helical linkers between proteins. Second, modularity has been achieved by engineering a DARPin component as an adaptor module; DARPins can be selected for binding to diverse protein molecules. The scaffold cores are based on cubically symmetric $(T)$ designed assemblies, providing additional advantages in symmetry for data processing and mitigation of the often recalcitrant problem of preferred orientation in cryo-EM. So far we have achieved a resolution of about $3.8 \AA$ for a $26 \mathrm{kDa}$ cargo protein, GFP.

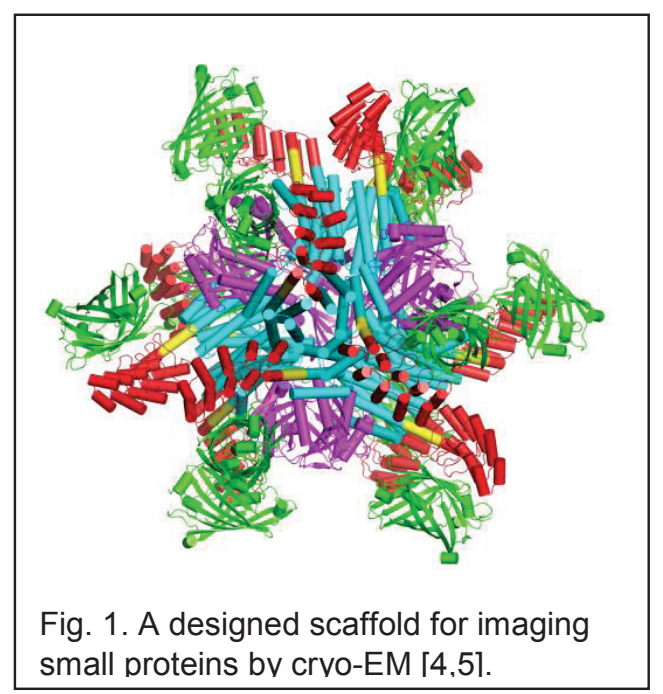

References:

[1] Herzik, M. A., Wu, M. \& Lander, G. C. (2019) Nat. Commun. 10, 1032.

[2] Yeates, T.O. (2017). Annu Rev Biophys. 46, 23-42.

[3] King, N.P, Sheffler, W., Sawaya, M.R., Vollmar, B.S., Sumida, J.P., André, I., Gonen, T., Yeates, T.O. \& Baker, D. (2012). Science 336, 1171-4.

[4] Liu, Y., Gonen, S., Gonen, T. \& Yeates, T.O. (2018). Proc Natl Acad Sci USA.115, 3362-3367.

[5] Liu, Y., Huynh, D.T. \& Yeates, T.O. (2019). Nat Commun. 10,1864. 